\title{
PENDIDIKAN BERKESETARAAN GENDER PERSPEKTIF PEMIKIRAN MUHAMMAD ATIYYAH AL-ABRASHI
}

\author{
Oleh: Syarifah Qamariah
}

\author{
Guru SDN 86 Talo Tenreng Sabbangparu Kabupaten Wajo
}

Email: syarifahqamariah@yahoo.com

\section{Abstract:}

This paper examines the gender equality education perspective of Muhammad Attiyah al-Abrashi's thought. Attiyah al-Abrashi is one of the leading figures in education. About twenty of his works speak of education. One interesting study described by 'Attiyah is the issue of liberty and equality education. Gender equality education in the 'Attiyah' perspective is the Islamic recognition of women's right to an unlimited education such as men. This recognition is also supported by historical facts about early educated women. There is freedom for women to learn from basic education to higher education, according to the individual interests of women. Basically the spirit of Islamic education is "freedom and democracy" that does not look at the sexes. Assuming that every human being (female / male) has the potential to be sharpened through education to be useful for building his world. In affirming the existence and role of women, 'Attiyah describes examples of women's professionalism from time to time.

\section{Abstrak:}

Tulisan ini mengkaji tentang pendidikan berkesetaraan gender perspektif pemikiran Muhammad Attiyah al-Abrashi. Attiyah al-Abrashi adalah salah seorang tokoh yang concern dalam dunia pendidikan. Kurang lebih duapuluhan karyanya berbicara tentang pendidikan. Salah satu kajian menarik yang dipaparkan oleh 'Attiyah adalah masalah pendidikan kebebasan dan kesetaraan.

Pendidikan berkesetaraan gender dalam perspektif 'Attiyah adalah pengakuan Islam atas hak perempuan dalam mengenyam pendidikan yang tiada batas seperti laki-laki. Pengakuan ini juga didukung oleh fakta-fakta sejarah tentang perempuan-perempuan terdidik pada masa awal. Ada kebebasan bagi perempuan untuk belajar dari mulai pendidikan dasar sampai pendidikan tinggi, sesuai minat masing-masing individu perempuan. Pada dasarnya ruh pendidikan Islam adalah "kebebasan dan demokrasi" yang tidak memandang jenis kelamin. Dengan asumsi bahwa setiap manusia (perempuan/laki-laki) mempunyai potensi yang harus diasah melalui pendidikan agar bermanfaat untuk membangun dunianya. Dalam mempertegas eksistensi dan peran perempuan, 'Attiyah mendeskripsikan contoh-contoh profesionalitas perempuan dari masa ke masa. 


\section{Kata Kunci: Pendidikan berkesetaraan gender, pemikiran, Muhammad Attiyah al-Abrashi, perempuan.}

\section{A. PENDAHULUAN}

Pendidikan merupakan sebuah proses untuk mengembangkan potensi manusia. Pada dasarnya jiwa manusia senantiasa dinamis dan selalu bergerak aktif dalam rentang kesinambungan pada suatu titik "mengoptimalkan potensi dinamisnya". Perbaikan kualitas bagi setiap manusia menjadi suatu keharusan. Pendidikan menjadi hak dan sekaligus kewajiban bagi setiap manusia untuk berubah, tidak terkecuali bagi perempuan.

Keadilan untuk mendapatkan hak dan menunaikan kewajiban adalah tujuan dalam hidup. Keadilan adalah gagasan paling sentral sekaligus tujuan tertinggi yang diajarkan setiap agama dan kemanusiaan dalam upaya meraih cita-cita manusia dalam kehidupan bersamanya. Abu Bakar al Razi (w. 865 M), menegaskan, "Tujuan tertinggi kita diciptakan dan kemana kita diarahkan bukanlah kegembiraan atas kesenangan fisik, tetapi pencapaian ilmu pengetahuan dan praktik keadilan.”

Keadilan secara umum didefinisikan sebagai "menempatkan sesuatu secara proposional" dan "memberikan hak kepada pemiliknya". Defenisi ini memperlihatkan sekaligus menunjukkan adanya keterkaitan dengan pemenuhan hak seseorang atas orang lain yang seharusya diterima tanpa diminta karena hak itu ada dan menjadi miliknya.

Salah satu wujud pemenuhan atas hak dan kewajiban setiap individu adalah pendidikan. Dalam term agama, pemenuhan kebutuhan akal dan spiritual dapat dilakukan dengan belajar untuk mendapatkan pengetahuan sebagai jalan untuk memahami agama dan membangun dunia.

Pendidikan dan menuntut ilmu dalam Islam menjadi sebuah keharusan. Dalam ayat yang pertama kali turun yaitu surat al-Alaq disebutkan kata Iqra' yang 
mempunyai makna membaca. Perintah ini menyiratkan pentingnya belajar melalui membaca untuk memahami semua fenomena yang ada di dunia. Nabi Muhammad SAW juga menegaskan kembali tentang kewajiban untuk mencari ilmu tanpa membedakan jender yaitu "talab al-ilmi faridatun 'ala kulli muslimun wa muslimatin". 2 Jadi pendidikan itu secara inklusif diperuntukkan untuk laki-laki dan perempuan. Karena pada dasarnya dalam Islam, ilmu adalah suci dan mencari ataupun menuntutnya adalah hak dan kewajiban bagi siapapun (laki-laki dan perempuan) tanpa adanya perbedaan.

Attiyah al-Abrashi adalah salah seorang tokoh yang concern dalam dunia pendidikan. Kurang lebih duapuluhan karyanya berbicara tentang pendidikan dan konsep pendidikan dalam perspektif Islam. Salah satu kajian menarik yang dipaparkan oleh 'Attiyah adalah masalah pendidikan kebebasan dan kesetaraan. Bagi 'Attiyah wacana kebebasan pendidikan atau "al-tarbiyah istiqlaliyah" tersirat makna kesetaraan untuk mendapatkan hak pendidikan. Dalam term lain secara khusus 'Attiyah juga mengupas tentang pentingnya pendidikan bagi kaum perempuan. Hal ini didasarkan pada historistas perkembangan Islam itu sendiri yang memang tidak menafikan peran perempuan dari masa ke masa. Berdasarkan paparan kerangka pikir tersebut maka kajian tentang pendidikan berkesetaraan gender perspektif pemikiran Muhammad Attiyah al-Abrashi perlu dikaji dalam penelitian ini.

\section{PEMBAHASAN}

\section{A. Biografi Muhammad 'Attiyah al-Abrashi}

Di dunia pendidikan, Muhammad 'Attiyah al-Abrashi memiliki sejumlah karya yang cukup popular khususnya dalam bidang pendidikan Islam $^{3}$ meskipun informasi tentang biografinya tersedia sangat terbatas.

Ada beberapa kemungkinan yang menyebabkan kepopuleran seseorang tidak banyak ditulis dan bukan merupakan hal yang penting. ${ }^{4}$ Pertama, karena sang tokoh

${ }^{2} \mathrm{M}$. Attiyah al-Abrashi, al Tarbiyah al-Islamiyah, (Mesir: IsaBabi al Halabi, t.t), h. 109.

${ }^{3}$ Muhammad 'Attiyah al-Abrashi, al-Tarbiyah wa Falasifuha (Bairut: Dar al Fikr, 1969), h.317-319. 
tidak suka publikasi, hal ini tampak dalam karya-karya " Attiyah yang tidak menginformasikan tentang dirinya. Kedua, gaya penulisannya yang kurang bombastis, ketiga, daya analisisnya yang kurang tajam. Inilah yang membuat kepopuleran seseorang menjadi terabaikan, sehingga kadang sulit untuk memprediksikan dan menilai sebuah konsep yang ditawarkan.

Karier intelektual 'Attiyah dalam dunia pendidikan tidak saja dilihat dari hasil karyanya saja, tapi lebih dilihat dari latar belakang intelektualnya yang merupakan salah satu sarjana muslim yang telah lama berkecimpung dalam dunia pendidikan di Mesir. Ada yang menyebutkan bahwa 'Attiyah adalah salah seorang guru besar' di fakultas Dar al Ulum Universitas Kairo $^{6}$ Terlepas dari minimya informasi tentang biografi 'Attiyah, namun karya-karyanya menunjukkan bahwa 'Attiyah adalah sosok tokoh yang sangat concern memunculkan pemikiran-pemikiran yang besar pengaruhnya dalam pendidikan Islam.

\section{B. Corak Pemikiran Attiyah}

'Attiyah termasuk ilmuan yang mempunyai pemikiran menarik, kreatif dan cukup inovatif pada masanya. Hal ini dilihat dari karya-karyanya yang terbit pada pertengahan abad ke-20, yang mewarnai corak pendidikan yang berkembang di Mesir. 'Attiyah adalah tokoh pendidikan yang sangat salut dengan kebijakan yang ditawarkan oleh pemerintahan Gamal Abdul Nassir yang berkuasa pada waktu itu. ${ }^{7}$

Dalam menjabarkan konsep pendidikan yang ideal Attiyah mencoba menggali dan mengamati apa yang terjadi di sekitarnya. Semuanya disesuaikan dengan segala perubahan, baik politik ataupun sosial, yang terjadi dalam masyarakat Mesir. 'Attiyah tetap berpegang teguh pada landasan idealisme umat Islam yaitu Al-Quran dan Hadis. Disamping itu, konsep-konsep pendidikan yang pernah diterapkan oleh para tokoh

${ }^{4}$ M. Muchydin Dimyati \& M. Rokib, Pendidikan Pembebasan (Yogyakarta: Aksara, 2000), h. 9 .

${ }^{5}$ Muhammad Atiyyah al-Abrasi, Ruh al Islam, Alih Bahasa: Syamsuddin Al Ahmad warid K \& Nizar Ali (Yogyakarta: Titian Ilahi Press, 1996), h. ix.

${ }^{6}$ http: / / ww. Cairo. Un. Eg / profile

${ }^{7}$ Atiyyah, Op. Cit., t.t, h. 5 
pendidikan terdahulu yang masih relevan dengan zaman tetap dipergunakan. Beberapa tokoh pendidikan muslim yang mempengaruhi pemikirannya diantaranya adalah; al-Ghazali, Ibnu Sina, al-Zarnuji, Ibu Khaldun, Ibnu Maskawaih, dan lainlain.

Hal penting yang menjadi catatan 'Attiyah dalam membangun sebuah konsep pendidikan (Islam) yang ideal utamanya adalah dalam rangka membangun mental dan akhlak para peserta didik tanpa mengabaikan elemen-elemen pendukungnya. Elemen-elemen tersebut diantaranya adalah:

a. Kebebasan dan demokrasi dalam pendidikan

b. Pembentukan akhlak sebagi tujuan utama pendidikan Islam

c. Manusia berbicara sesuai dengan kemampuannya

d. Variasi dalam mempergunakan metode yang dipakai dalam pengajaran

e. Pendidikan Islam adalah pendidikan kemerdekaan (bebas)

f. Sistem pendidikan individu dalam pendidikan Islam

g. Perhatian atas pembawaan (bakat alamiah/potensi) seseorang dalam tuntutan pada bidang-bidang yang dipilihnya

h. Mencintai ilmu dan mempersiapkan diri dalam belajar

i. Pendidikan bagi perempuan dalam Islam, dan

j. Pelayanan terhadap peserta didik secara halus. ${ }^{8}$

Dengan demikian, konsepsi 'Attiyah tentang konsep pendidikan adalah komperehensif, mulai dari pendidik, peserta didik, materi (kurikulum), pengelolaan pembelajaran, interaksi edukatif serta pemenuhan hak dan kewajiban bagi setiap peserta didik. Termasuk salah satunya adalah urgensi pendidikan berkesetaraan gender. Namun demikian bagi 'Attiyah semua konsep tersebut lebih ditekankan akan pentingnya aspek moral. Hal inilah yang dijadikan dasar untuk membangun ide-ide tentang konsep pendidikan Islam ideal, dengan didukung prinsip-prinsip demokrasi dan kemerdekaan sebagai wujud kemandirian.

\section{Hakikat Manusia dan kebebasan}

Konsep manusia penting untuk dikaji. Hal ini bukan semata demi pengetahuan manusia saja tetapi karena konsep tersebut merupakan syarat bagi pembenaran kritis

${ }^{8}$ Ibid. 
dan landasan yang aman bagi pengetahuan manusia, sebagai landasan untuk mengembangkan lingkungannya. Hal ini dapat terwujud karena manusia mempunyai kebebasan untuk memilih dan merespon apa yang terjadi di dalam kehidupannya.

Manusia didefinisikan sebagai satu-satunya makhluk di alam semesta yang memiliki ruh ilahi dan bertanggung jawab terhadap amanat Allah ${ }^{9}$ untuk mewujudkan kemanusiaannya. Manusia mempunyai substansi yang mandiri dan memiliki kehendak bebas, dengan pengertian bahwa manusia sebagai sebab awal yang mandiri, yang menjadikan masyarakat dan sejarah merupakan kelanjutan mutlak baginya dalam mata rantai atas kemerdekaan dan kebebasan memilih, sehingga manusia disebut makhluk yang krearif. Kreatifitasnya inilah yang menyatukan perbuatannya sehingga, manusia mampu menjadikan dirinya makhluk yang sempurna.

Manusia mempunyai historisitas, ${ }^{10}$ karena manusia adalah pelaku sejarah dalam mata rantai kehidupan yang orientasinya menjangkau tiga dimensi waktu; yaitu lampau, kekinian, dan masa mendatang, ${ }^{11}$ untuk membangun dunia dan lingkungan yang dicita-citakan yaitu dunia yang tidak hanya sekedar memberinya kehidupan dan hidup. Manusia tidak dapat membiarkan semua berkembang secara naluri tanpa adanya kreatifitas dan inovasi. Oleh karena itu diperlukan suatu kesadaran ${ }^{12}$ untuk menentukan pilihan yang mengisyaratkan adanya kebebasan yang bersifat terbuka pada diri manusia ke jalan Tuhan. Di sinilah arti penting manusia untuk menetukan arah hidupnya selanjutnya. Namun kehendak yang diinginkan manusia harus tetap

\footnotetext{
${ }^{9}$ AliSyari'ati, Humanisme: Antara Islam dan Mazhab Barat, Bandung: Pustaka Hidayat, 1996), h.47.

${ }^{10}$ Abdurahman Wahid, dalam Tim LKIS, “Nahdatul Ulama” dalam ( BASIS, No 5-6 th. Ke45, Agustus, 1996),h. 377)

${ }^{11}$ Mastuhu, Memberdayakan Sistem Pendidikan Islam: Strategi Budaya Menuju Masyarakat Akademik, (Jakarta: Logos Wacana Ilmu, 1999),h. 22

${ }^{12}$ M.Sastra Pratedja, "Pembangunan pendidikan Berwawasan Kemanusiaan", dalam (INOVASI, No. 1 Tahun VIII, 1998), h.16
} 
tunduk pada kekuasaan Allah. Kemerdekaan kehendak (huuriyat al-irodah) membawa manusia menjunjung tinggi arti dan nilai kehidupan. ${ }^{13}$

Bagaimana mewujudkan eksistensi manusia yang lebih manusiawi? Ini adalah sebuah pertanyaan yang mudah untuk dijawab tetapi sangat sulit untuk direalisasikan. Sebab manusia dengan segala kebebasan yang dimilikinya tidaklah utuh, masih ada sekat-sekat yang selalu membelenggu kebebasannya, baik dalam diri manusia sendiri atau lingkungan yang membentuknya. Inilah yang menjadi ide awal bagi 'Attiyah. Kebebasan merupakan dua hal yang membuat manusia lebih berkualitas. Manusia tidak hanya menjadi objek penderita, tetapi dapat menjadi subjek yang kreatif.

Manusia dan kebebasan dalam pandangan 'Attiyah tidak terlepas dari defenisi-defenisi yang dibentuk oleh kaidah-kaidah yang sudah baku, al-Quran dan Hadis, sebagai dasar bagi umat Islam memberikan kebebasan bagi manusia dengan porsi yang cukup tinggi. Dalam menjabarkan tentang manusia dan kebebasannya, 'Attiyah melihat bahwa, Islam memberikan dasar-dasar kebebasan bagi manusia sebagai makhluk yang sempurna, yaitu dengan diberinya akal agar manusia dapat berfikir. Hal ini dinyatakan sebagi berikut :

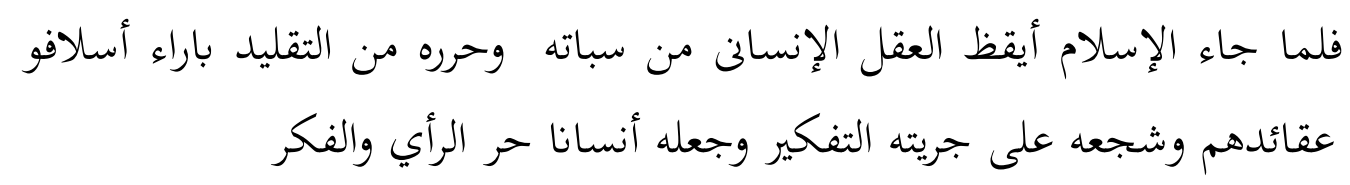

"Ketika Islam datang membangkitkan akal manusia dari tidurnya, membebaskannya dari kekangan keterbatasan pemikiran orang-orang terdahulu serta keyakinan mereka, dan mendorongnya untuk bebas berfikir, dan menjadikannnya sebagai manusia yang bebas berpendapat dan berfikir" 14

Kebebasan berfikir dalam Islam sebenarnya telah mampu mengubah pendirian oerang-orang terdahulu sebelum kedatangan Islam, yaitu orang-orang yang mengikuti

\footnotetext{
${ }^{13}$ Abdurrahman Wahid, op. cit., h. 58.

${ }^{14}$ Athiyyah, op.Cit., t.t., h. 138
} 
saja (taqlid) tanpa berfikir, mengikuti pendahulunya, ${ }^{15}$ atau menganggap telah dapat petunjuk dengan mengikuti nenek moyang mereka. ${ }^{16}$

'Attiyah melihat bahwa kebebasan itu relatif. Bila dikatakan bahwa manusia adalah makhluk liberal atau bebas, maka yang dimaksud bebas adalah bebas dalam menentukan sikap tanpa ada belenggu dan kekangan. Makna bebas adalah menentukan sikap terhadap segala aturan, tanggung jawab atau beban yang telah ditetapkan kepada mereka sebelumnya, dan boleh menentukan masa depan. ${ }^{17}$ Jadi kebebasan yang dikehendaki 'Attiyah adalah kebebasan yang erat kaitannya dengan pemikiran individu untuk berfikir lebih kreatif dalam menjalankan tanggung jawabnya.

'Attiyah melihat bahwa kebebasan yang dimiliki oleh setiap manusia tidak hanya untuk kepentingan individu semata, tapi juga untuk kepentingan orang lain atau kepentingan masyarakat banyak. Karena pada dasarnya manusia adalah makhluk sosial (homososial) yang selalu berinteraksi dengan lingkungan sekitarnya. Manusia dapat bertahan karena faktor campur tangan orang lain. 'Attiyah menulis:

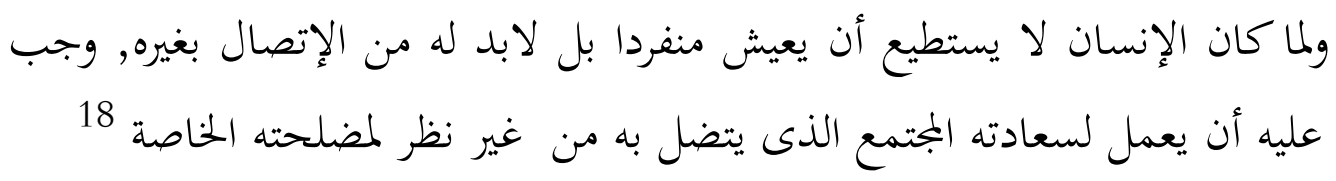

Artinya;

"Karena manusia tidak dapat hidup sendiri, harus berinteraksi dengan lainnya, maka manusia harus berbuat sesuatu untuk kesejahteraan sosial dimana ia berinteraksi, tanpa memandang kepentingan individual semata."

Posisi manusia sebagai makhluk sosial tidak akan lepas dari lingkungannya.

Bahkan situasi dan kondisi lingkungan tersebut sangat mempunyai dampak hampir dominan dalam memberikan warna dan budaya tertentu bagi kehidupan manusia selanjutnya, sifat manusia akan sangat terpengaruh oleh kondisi tersebut. Namun hal

${ }^{15}$ Lihat QS. Luqman:21

${ }^{16}$ Lihat ibid., al-Zukhruf:22

${ }^{17}$ Atiyyah al-Abrasyi, Ittijahati al-Hadatisash filal-Tabiyah, (Mesir: Isa Babi Al Halabi: 1943), h. 16

${ }^{18}$ Athiyyah, op.cit., t.t., h. 27. 
ini bukanlah sebuah ukuran untuk menentukan sifat-sifat manusia, apakah itu baik atau buruk. Tidak dapat dipungkiri bahwa kondisi sosio cultural masyarakat juga turut andil dalam menentukan prilaku baik buruknya manusia, tapi hal itu menjadi barometer yang mutlak bagi perkembangan perilaku manusia.

Barometer baik dan buruknya perilaku manusia tergantung pada nilai ketundukan manusia terhadap nilai-nilai kepercayaan (iman) kepada yang membuat aturan, yakni Allah. Bila masalah ini dikaitkan dengan nilai-nilai agama, maka norma Islamlah yang berlaku. 'Attiyah menyebutkan bahwa manusia itu dapat menerima sifat atau nilai-nilai luhur (baik) dan buruk, karena manusia dilahirkan dalam keadaan fitrah, kemudian lingkungan mempengaruhinya untuk menjadi baik atau buruk. ${ }^{19}$

'Attiyah menyatakan dalam diri dan sifat manusia adalah sesuatu yang tetap dan tidak pernah berubah. Disinilah faktor keseimbangan yang menjadi sebuah mata rantai yang mengelilingi kehidupan manusia, yaitu keseimbangan faktor lingkungan; masyarakat, keluarga, dan budaya dengan faktor dasar, fitrah.

'Attiyah memandang manusia dalam pandangan teosentris. Teo-sentris yang dimaksud adalah pandangan tentang manusia sempurna (al-Insan al-kamil) yaitu manusia yang beramal, memiliki suri tauladan mulia, sifat terpuji, beribadah kepada Allah semata, sesuai dengan norma yang berlaku dalam lingkungan dan norma agama, karena Allah melarang manusia untuk mengikuti sesuatu yang tidak diketahui. Allah melarang manusia bersikap sombong dan angkuh saat berjalan, sebaliknya dianjurkan bersikap tawadhu', merendahkan diri. ${ }^{20}$ Pandangan tersebut menunjukkan besarnya perhatian 'Attiyah berdasarkan hasil penelahan atas konsep Islam tentang manusia sebagai makhluk etic-religious.

Apa yang diharapkan 'Attiyah tentang manusia dan eksistensinya adalah bahwa manusia tidak hanya sekedar makhluk berbeda dari makhluk lainnya, yang mempunyai unsur-unsur eksternal sebagai wujud untuk membentuk dunianya.

\footnotetext{
${ }^{19}$ Ibid., h. 12

${ }^{20}$ Ibid., h.171
} 
Oleh karena itu sesuai dengan prinsip-prinsip dasar Islam. 'Attiyah mencoba menggali hakikat kemanusiaan berdasarkan potensi yang dimilikinya disesuaikan dengan tingkat potensialnya. Kesempurnaan yang dimiliki manusia secara fisik diwujudkan dengan kesempurnaan yang dimiliki manusia secara fisik diwujudkan dengan kesempurnaan komponen-komponen pembentuknya yang dimiliki oleh makhluk lain, yaitu komponen rohani yang berupa potensi yang disebut fitrah, hati, dan akal. ${ }^{21}$ Jika potensi ruhaniah yang dimiliki manusia tidak digunakan secara maksimal, maka sama seperti binatang atau bahkan lebih rendah derajatnya dari itu. Sedangkan bentuk insaniyahnya bergantung pada iman dan amal.

Potensi yang dimiliki manusia tidak akan berkembang tanpa adanya kebebasan maka sebagai makhluk liberal manusia harus menggunakan kebebasan yang dimilikinya untuk membangun dunianya. Liberasi manusia yang paling penting adalah kebebasan dalam menentukan kepercayaan (agama) sebagai kebebasan puncak (Q.S; 1:256 dan Q.S; 10:99). Selanjutnya adalah kebebasan dalam menentukan pilihan, demi tercapainya kebaikan bagi dirinya dan lingkungan. manusia bebas berbuat dan memikul dosa orang lain, tapi harus bertanggung jawab terhadap perbuatan yang dilakukannya, sebagai pemangku amanat dari tuhan.

Kebebasan yang dimiliki manusia mempunyai beberapa tingkatan. ${ }^{22}$ Pertama kebebasan sebagai lawan dari perbudakan. Kedua, kebebasan akidah dan kebebasan berpikir yang keduanya merupakan nilai eksistensial kemanusiaan. Ketiga, kebebasan berkehendak adalah kebebasan yang paling sulit karena yang mendasarinya adalah amanat kemanusian yang dibawa manusia sebagai khalifah di bumi, sebagai wujud pertanggung jawabannya terhadap Allah Swt menuju manusia sempurna.

Kesempurnaan manusia tidak hanya dilihat dari kesempurnaan fisik, tapi ditinjau dari bagaimana manusia itu menggunakan potensinya, yaitu kemampuan

\footnotetext{
${ }^{21}$ Lihat Q.S: 95: 4, dan Q.S: 327

${ }^{22}$ Aisyah Abdurahman, Manusia Sensivitas Hermeneutika Al-Quran, Alih Bahasa: Adib alArif, (Yogyakarta: LKPSM, 1997),h. 77
} 
mengaktualisasikan dirinya sebagai makhluk Allah (habl min allah) dan makhluk sosial (habl min alnas) dalam membangun dunia.

\section{Pendidikan Berkesetaraan Gender dalam Perspektif Atiyyah Al-Abrashi}

Kewajiban dan hak menuntut ilmu berlaku untuk semua orang tidak pengecualian termasuk bagi perempuan. Dalam Islam, ilmu adalah suci dan menuntutnya adalah sebuah kewajiban. Hal ini ditegaskan oleh nabi SAW.

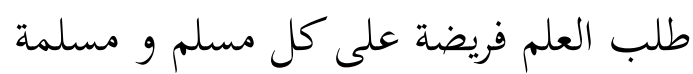

Artinya:

"Mencari ilmu adalah kewajiban bagi setiap orang Islam, baik laki-laki maupun perempuan".

Kesetaraan pendidikan bagi perempuan perspektif Atiyyah mendapatkan legitimasi historis dalam sejarah keterlibatan perempuan Arab era jahiliyah dalam pendidikan. Hal ini dibuktikan dengan adanya beberapa perempuan yang sudah yang berprofesi sebagai penulis dan penyair. Ketika Islam datang kehidupan intelektual bagi perempuan (muslimah) justru tumbuh pesat dan mereka mendapatkan hakhaknya dalam masyarakat. Dalam konteks historis masa kegemilangan Islam, perempuan-perempuan yang sudah "melek huruf” diantaranya adalah Hafsah (istri nabi SAW), Asiyah binti Sa'd dan Aisyah binti Abu Bakar. Perempuan-perempuan muslimah yang cerdas dan professional dalam bidang sastra sebagai kategori penyair dan kritikus sastra diantaranya adalah khansa', Sakinah binti Husain R.A dan Aisyah binti Tholhah (kritikus sastra).

Dalam buku-buku berbahasa Arab telah ditulis beberapa nama perempuan muslimah yang professional di bidang agama, sastra, kedokteran dan seni dari masakemasa diantaranya: (1) Aliyah binti Al-Mahdi (penyair) (2) Aisyah binti Ahmad bin Qodim (penyair), (3) Wiladah binti Al Mustaqli Billah (penyair), (4) Lubna (penyair), (5) Fadhil ( seniwati dan sastrawan), (6) Zainab; dokter Bani Aud di bidang mata, (7) beberapa perempuan yang berkiprah dalam penyelematan nyawa dalam 
peperangan, (8) Umayyah binti Qois Al-Ghofariyah dan Al-Rabi binti Maudz (telibat dalam perang nabi SAW) (9) Ummul Hasan binti Al-Qhodi abi Ja'far Attonjali.

Data historis para perempuan terdidik tersebut, memberikan legitimasi atas seruan nabi tentang pentingya pendidikan bagi laki-laki dan perempuan. Sejarah memberikan fakta-fakta perempuan memiliki peran yang mewarnai berbagai dimensi kehidupan. Dengan demikian, profesionalitas tidak bergantung dari sudut jenis kelamin tetapi ditentukan oleh kemampuan setiap individu. Berdasarkan kenyataan sejarah tersebut, bagi Atiyyah, perempuan (muslimah) tidak hanya cukup dengan belajar secara teoritis saja, namun harus mampu memanfaatkan dan mengaplikasikan dalam bidang kehidupan sebagai seorang yang professional.

Pengakuan Islam atas hak perempuan dalam mengenyam pendidikan yang tiada batas. Ada kebebasan bagi peremuan untuk belajar dari mulai pendidikan dasar sampai pendidikan tinggi, sesuai minat masing-masing individu perempuan. Pada dasarnya ruh pendidikan Islam adalah "kebebasan dan demokrasi" yang tidak memandang jenis kelamin. Dengan asumsi bahwa setiap manusia (perempuan/lakilaki) mempunyai potensi yang harus diasah melalui pendidikan agar bermanfaat untuk membangun dunianya.

Perempuan harus membekali diri dengan ilmu sebagai pembuka cakrawala dan akhlak yang baik. Kesetaran antara laki-laki dan perempuan dapat dilihat dari kemampuan dan ilmu pengetahuan yang dimiliki. ${ }^{23}$ Hal ini menunjukkan eksistensi seseorang. Peran pendidik perempuan dapat dimulai dari keluarga. Dengan mengutip syair dari Hafiz Ibrahim, Atiyyah mencoba mengukuhkan kontribusi perempuan dalam pendidikan sebagai berikut :

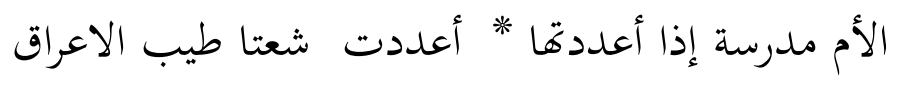

Artinya: Ibu adalah sekolah jika dipersiapkan dia dengan baik, maka sungguh telah mempersiapkan generasi masa depan lebih baik.

\footnotetext{
${ }^{23}$ Muhammad 'Attiyah al-Abrashi, op.cit: t.t 1969, h.115.
} 
Atiyyah memberikan pandangan tentang pendidikan sebagai sarana untuk mengembangkan kemandirian potensi dan eksistensi diri. Pendidikan bagi perempuan adalah wujud dari eksistensi dirinya dalam mengembangkan potensi untuk menjadi insan yang professional di bidangnya. Contoh-contoh, kiprah perempuan yang dipaparkan Atiyyah dalam konteks sejarah menunjukkan bahwa perempuan memiliki peran yang seimbang dengan laki-laki dari masa ke masa.

\section{PENUTUP}

Urgensi pendidikan terletak pada pengembangan potensi untuk menjadi manusia yang mandiri. Pendidikan menjadi hak setiap orang tidak terkecuali bagi perempuan. Islam menempatkan pentingnya pendidikan bagi setiap orang sebagai hak dan kewajiban.

Pendidikan berkesetaraan gender dalam perspektif 'Attiyah adalah pengakuan Islam atas hak perempuan dalam mengenyam pendidikan yang tiada batas. Pengakuan ini juga didukung oleh fakta-fakta sejarah tentang perempuan-perempuan terdidik pada masa awal. Ada kebebasan bagi perempuan untuk belajar dari mulai pendidikan dasar sampai pendidikan tinggi, sesuai minat masing-masing individu perempuan. Pada dasarnya ruh pendidikan Islam adalah "kebebasan dan demokrasi" yang tidak memandang jenis kelamin. Dengan asumsi bahwa setiap manusia (perempuan/laki-laki) mempunyai potensi yang harus diasah melalui pendidikan agar bermanfaat untuk membangun dunianya. Dalam mempertegas eksistensi dan peran perempuan, 'Attiyah mendeskripsikan contoh-contoh profesionalitas perempuan dari masa ke masa.

\section{SUMBER RUJUKAN}

Abdurrahaman Wahid dalam Tim LKIS, “ Nahdatul Ulama” dalam BASIS, No 5-6 th. Ke- 45, Agustus, 1996, Aisyah Abdurrahman, Manusia Sensivitras Hermeneutika Al-Quran, Alih Bahasa: Adib al-Arif, Yogyakarta: LKPSM, 1997

Ali Syari'ati, Humanisme: Antara Islam dan Mazhab Barat, Bandung: Pustaka Hidayat 
Anton Bekker \& Ahmad Charis Zubair. Metodologi Penelitian Filsafat, Yogyakarta: Kanisius, 1990

Http:/ / www. Cairo. Un. Eg/profile. Html

Louis Lehey, "Manusia dan Historisitasnya”, dalam Basis, Edisi Oktober, 1996

M. Muchyidin Dimyati dan M. Rokib, Pendidikan Pembebasan, Yogyakarta: Aksara, 2000.

M. Sastra Prateja, "Pembangunan Pendidikan Berwawasan Kemanusiaan”, dalam INOVASI, No. 1 Tahun VIII, 1998.

Mastuhu, Memberdayakan Sistem Pendidikan Islam: Strategi Budaya Menuju Masyarakat Akademik, Jakarta: Logos Wacana Ilmu, 1999.

Muhammad 'Attiyah al-Abrashi, al-Tarbiyah wa Falasifuha, Bairut: Dar al Fikr, 1969.

, (t.t) al Tarbiyah al-Islamiyah, Mesir: Isa Bab al Halabi, t.t. , Ittijahati al-Hadatisash filal-Tabiyah, Mesir: Isa Bab Al Halabi, 1943.

, Ruh al Islam, Alih Bahasa: Syamsuddin Al Ahmad warid K \& Nizar Ali, Yogyakarta: Titian Ilahi Press, 1996.

, Ruh al-Tarbiyah wa al-Tali'lim, Mesir: Isa Bab al-Halabi.

Najlah Naqiyah, Otonomi Perempuan, Malang: Bayumesia Publishing, Zoes. 